\title{
A genome-wide association study in catfish reveals the presence of functional hubs of related genes within QTLs for columnaris disease resistance
}

\author{
Xin Geng ${ }^{1}$, Jin Sha², Shikai Liu', Lisui Bao', Jiaren Zhang ${ }^{1}$, Ruijia Wang ${ }^{1}$, Jun Yao ${ }^{1}$, Chao Li ${ }^{1}$, Jianbin Feng ${ }^{1}$,

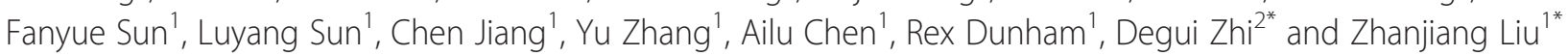

\begin{abstract}
Background: Columnaris causes severe mortalities among many different wild and cultured freshwater fish species, but understanding of host resistance is lacking. Catfish, the primary aquaculture species in the United States, serves as a great model for the analysis of host resistance against columnaris disease. Channel catfish in general is highly resistant to the disease while blue catfish is highly susceptible. F2 generation of hybrids can be produced where phenotypes and genotypes are segregating, providing a useful system for QTL analysis. To identify genes associated with columnaris resistance, we performed a genome-wide association study (GWAS) using the catfish $250 \mathrm{~K}$ SNP array with 340 backcross progenies derived from crossing female channel catfish (Ictalurus punctatus) with male F1 hybrid catfish (female channel catfish I. punctatus $\times$ male blue catfish I. furcatus).
\end{abstract}

Results: A genomic region on linkage group 7 was found to be significantly associated with columnaris resistance. Within this region, five have known functions in immunity, including pik3r3b, cyld-like, adcyap1r1, adcyap1r1-like, and mast2. In addition, 3 additional suggestively associated QTL regions were identified on linkage groups 7, 12, and 14. The resistant genotypes on the QTLs of linkage groups 7 and 12 were found to be homozygous with both alleles being derived from channel catfish. The paralogs of the candidate genes in the suggestively associated QTL of linkage group 12 were found on the QTLs of linkage group 7. Many candidate genes on the four associated regions are involved in PI3K pathway that is known to be required by many bacteria for efficient entry into the host.

Conclusion: The GWAS revealed four QTLS associated with columnaris resistance in catfish. Strikingly, the candidate genes may be arranged as functional hubs; the candidate genes within the associated QTLs on linkage groups 7 and 12 are not only co-localized, but also functionally related, with many of them being involved in the PI3K signal transduction pathway, suggesting its importance for columnaris resistance.

Keywords: Columnaris, Disease resistance, Bacteria, Immunity, GWAS, PI3K, Hybrid, Fish, QTL

\section{Background}

Commercial production of catfish (Ictalurus spp.) accounts for approximately $60 \%$ of US aquaculture production (www.ers.usda.gov). However, due to devastating diseases, the catfish industry has been hindered by unprecedented challenges. Diseases can cause losses of up to one third of the industry each year. Flavobacterium

\footnotetext{
*Correspondence: dzhi@uab.edu; liuzhan@auburn.edu

${ }^{2}$ Department of Biostatistics, University of Alabama at Birmingham,

Birmingham, AL 35294, USA

${ }^{1}$ Fish Molecular Genetics and Biotechnology Laboratory, Aquatic Genomics Unit, School of Fisheries, Aquaculture and Aquatic Sciences and Program of Cell and Molecular Biosciences, Auburn University, Auburn, AL 36849, USA
}

columnare, a Gram-negative bacterium, is the causative agent of columnaris disease, which is very common in wild and cultured freshwater fish worldwide [1]. This pathogen can infect a variety of fish species through mucosal attachment points on the gill and skin, causing external erosion and necrosis [2]. The bacterium can also enter the blood stream and invade the internal organs [3]. The economically important foodfish channel catfish (Ictalurus punctatus) and the other members of the family Ictaluridae are extremely susceptible to columnaris disease. Columnaris disease is considered as one of the most important diseases in the catfish industry, causing 
tens of millions of dollars in losses every year [2]. Therefore, improving disease resistance is a major goal for genetic stock enhancement using various approaches including strain selection, crossbreeding, hybridization, and transgenics [4].

Heterosis is an important genetic force that contributes to world food production. Interspecific hybrids are particularly effective in generating significant heterosis [5]. Hybrids of catfish have been investigated for about 50 years [6]. Among all possible combinations, only one cross (female channel catfish $\times$ male blue catfish) exhibited better performance than its parental species in growth rate and feed conversion efficiency [7].

Various techniques have been used to dissect the genes responsible for production and performance traits in aquaculture species. For instance, traditional QTL mapping was conducted to locate the region associated with resistance to infectious pancreatic necrosis virus in Atlantic salmon (Salmo salar) [8-13]. Utilizing RNA-seq, $\mathrm{Li}$ et al. [14] characterized the role of catfish intestinal epithelial barrier following enteric septicemia of catfish (ESC, Edwarsiella ictaluri) challenge. Wang et al. [15] conducted bulked segregant analysis to study candidate gene locations and allele-specific expression associated with ESC resistance in catfish. However, genetic analysis of resistance against bacterial diseases such as columnaris has been limited.

In the last decade, various studies were conducted aiming at elucidating the mechanisms of columnaris entry, immune evasion, and the host response to the disease. Some studies have been conducted on the modes and dynamics of columnaris adhesion [16,17]. In recent years, the application of RNA-seq has allowed a significantly greater level of understanding of the complexities of columnaris induced gene expression [18]. Several central signatures following infection were revealed by gene expression enrichment analysis and gene pathway analysis of differentially expressed genes [18]. For instance, Beck et al. [19] revealed that rhamnose-binding lectin was induced dramatically after infection, which was correlated with columnaris susceptibility. Peatman et al. [20] carried out RNA-seq analysis to compare basal and postchallenge differences in expression between susceptible and resistant channel catfish lines. Some genes involved in critical innate immunity, such as iNOS2b, lysozyme C, IL8 , and TNF-alpha were constitutively expressed higher in resistant than in susceptible catfish gill tissues. In contrast, secreted mucin forms, rhamnose-binding lectin, and some mucosal immune factors were found to be expressed at higher levels in the susceptible catfish line than in the resistant line. Despite these efforts, the knowledge of molecular mechanism of columnaris resistance is still limited.

Genome-wide association mapping allows detection of markers closely linked to QTLs. Although QTL mapping is well-suited for family-based samples, association studies, especially genome-wide association studies, can potentially offer higher mapping resolution using markers with higher density. Moreover, recent developments in GWAS methodologies have offered mature software packages for association analysis. Although GWAS has been widely utilized in economically important plants [21] and animals [22,23], it has been seldom applied in fish. To identify the QTLs in the hybrid catfish related to columnaris resistance, a genome-wide association study using backcross hybrid catfish was conducted, and here we report the identified QTLs and their associated genes within the highly associated genomic regions.

\section{Results}

\section{Mortality rate}

The accumulative mortality rate was $45.7 \%$. A total of 1,200 channel catfish from a mix of six families were pooled and communally challenged. The mortalities started 46 hours after challenge and peaked approximately 218 hours after challenge (Figure 1). Based on the selective genotyping method [24], the blood samples of the first 169 dead fish were collected, serving as the "susceptible" fish. After 12 days of challenge, 652 fish survived. From the survivors, 171 fish without symptoms of columnaris were randomly collected as the "resistant" fish.

\section{Sample structure}

The founders of the 6 families were known before the experiment, but the offspring were mixed for communal culture. In order to assign the genotyped fish to each of the six families, cluster analysis was conducted according to the IBS kinship matrix (Table 1). With known family pedigree, principal component analysis was conducted using eigenvalues as coordinates to visualize the sample structure. As shown in Figure 2, apparently, families 4, 5 , and 6 were highly related, while families 1,2 , and 3 were distantly related.

\section{Analysis of linkage disequilibrium (LD) blocks}

The LD block was defined as a set of contiguous SNPs with the minimum pairwise $r^{2}$ value exceeding 0.50 [22]. The number of independent SNP markers and LD blocks was 14,420. Thus the threshold P-value for genome-wide significance was $0.05 / 14420=3.47 \mathrm{e}-6\left(-\log _{10}\right.$ $(\mathrm{P}$-value $)=5.46)$. The threshold P-value for the significance of "suggestive association", which allows one false positive effect in a genome-wide test, was $1 / 14420=6.93 \mathrm{e}-5\left(-\log _{10}\right.$ $(\mathrm{P}$-value $)=4.16)$.

\section{Linkage groups with associated QTLs for columnaris resistance}

A Manhattan plot constructed using the marker positions and the corresponding $-\log _{10}(\mathrm{P}$-value) is shown in 


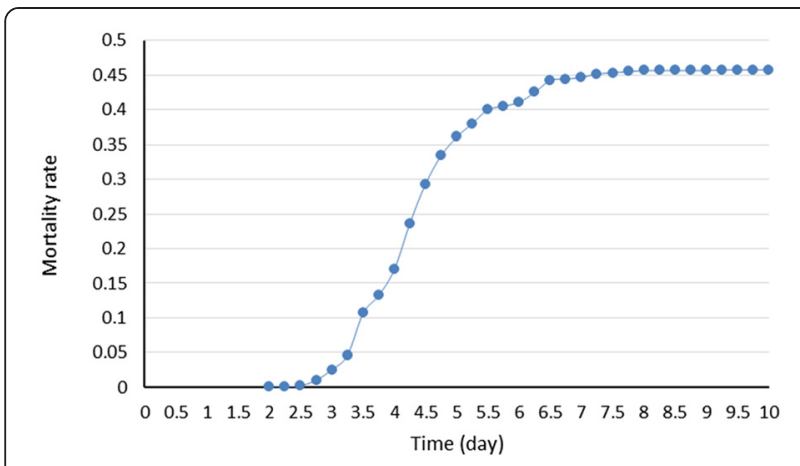

Figure 1 Mortality rate of hybrid catfish after Flavobacterium columnare infection.

Figure 3. Linkage group 7 harbors markers that are statistically significant at the genome level $\left(-\log _{10}\right.$ (P-value) $>$ 5.46). A second genomic region on linkage group 7 appears to harbor suggestively associated markers, but is not statistically significant at the genome level. In addition to linkage group 7, linkage groups 12 and 14 appear to harbor SNP markers that are also suggestively associated with columnaris resistance, although not statistically significant at the genome level (Figure 3).

\section{Genomic region with significantly associated QTL for columnaris resistance}

Additional analysis was conducted with the chromosomal region where the significantly associated QTL is located on linkage group 7. A set of 12 most significant SNPs are listed in Table 2. These SNPs are all significantly associated with columnaris resistance at the genome level $\left(-\log _{10}(\mathrm{P}\right.$-value $\left.)>5.46\right)$. These SNPs are all located in a genomic region on linkage group 7 from $7,203,819$ bp to $7,817,023 \mathrm{bp}$, spanning a total of approximately $620 \mathrm{~Kb}$. Their minor allele frequencies vary between 0.24-0.39, and their nearby genes are listed in Table 2. Because family-based population with 8 founders were utilized, the haplotypes extend very long regions as expected (Figure 4).

EMMAX was used to investigate the contribution of the significantly associated QTL to the phenotype. Because of high correlation between SNPs in one locus (Figure 4 and Section Correlation of the SNPs associated with columnaris resistance), when analyzing the fraction of variance explained by the QTL, we chose only the most significant SNP (AX-86060479) to represent this region, which could explain $6.6 \%$ of the phenotypic variance. Nevertheless, binary phenotype and selective genotyping used in our study may cause potential overestimation of the QTL effect.

Based on the SNPs placed on the catfish $250 \mathrm{~K} \mathrm{SNP}$ panel [25], the parental origins of the SNPs could be determined. All the 12 significant SNPs are interspecific, which means on these loci, two species are simply fixed for alternate alleles. The resistant genotypes for the 12 SNP loci are homozygous with both alleles being originated from channel catfish.

\section{Genes located within the significantly associated QTL region for columnaris resistance}

The genes within the genomic region harboring the significant SNPs associated with columnaris resistance were annotated by BLAST analysis against the non-redundant protein database [26]. To provide additional supporting evidence for the proper annotation of the region, syntenic analyses were also conducted to compare the gene contents in the genomic neighborhood around the significant SNPs. As shown in Figure 4, the conserved synteny was identified between the catfish and zebrafish genomes. The flanking genes of catfish are all conserved with zebrafish except efcab7 and tspan1 are missing in catfish and the gene orders are slightly different.

Within the $620 \mathrm{~Kb}$ region containing the most significant SNPs, a total of 10 genes were identified (Figure 4). Of the 10 genes, five genes were found to have known functions in immunity, and these include phosphatidylinositol 3kinase regulatory subunit gamma b (pik3r3b), cylindromatosis-like (cyld-like), pituitary adenylate cyclase-activating polypeptide type 1 receptor (adcyap1r1), adcyap1r1-like, and microtubule-associated serine and threonine kinase 2 (mast2). In order to be sure all the candidate genes were included in the analysis, the extended genomic region was examined, and no gene was found with known function in immunity.

Table 1 The pedigree information of catfish samples used in this study

\begin{tabular}{llllll}
\hline Family ID & Dam & Sire & $\begin{array}{l}\text { Sample } \\
\text { number }\end{array}$ & $\begin{array}{l}\text { Susceptible } \\
\text { sample number }\end{array}$ & $\begin{array}{l}\text { Resistant } \\
\text { sample number }\end{array}$ \\
\hline 1 & Channel 1 & Hybrid 1 & 96 & 48 & 48 \\
2 & Channel 2 & Hybrid 1 & 95 & 47 & 48 \\
3 & Channel 3 & Hybrid 2 & 55 & 28 & 27 \\
4 & Channel 4 & Hybrid 1 & 14 & 8 & 6 \\
5 & Channel 5 & Hybrid 1 & 27 & 18 & 9 \\
6 & Channel 6 & Hybrid 1 & 53 & 20 & 33 \\
\hline
\end{tabular}




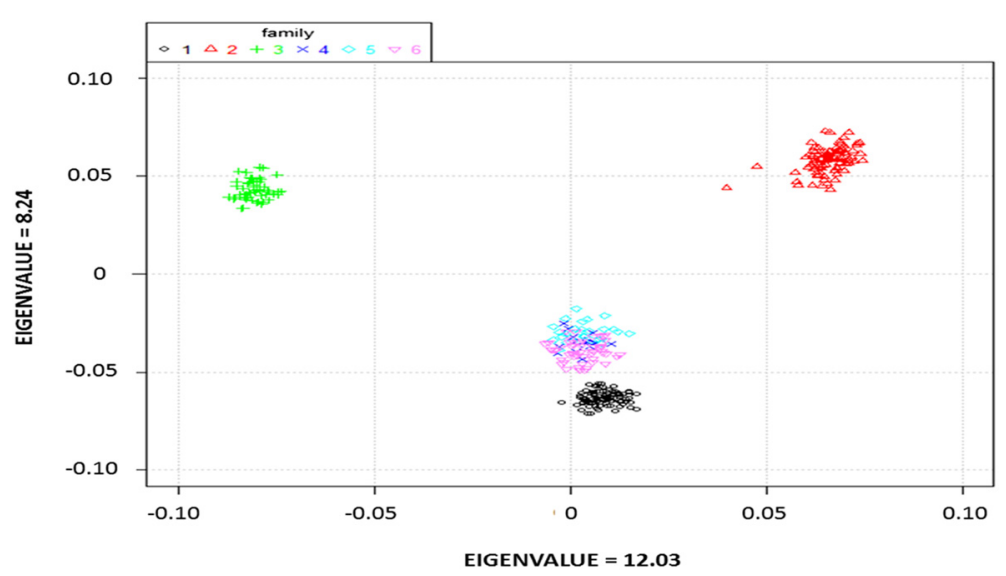

Figure 2 Sample structure identified by PCA with the first two principal components. The coordinates are the first two principal components.

\section{Suggestively associated QTLs}

In addition to the significantly associated QTL on linkage group 7, three additional genomic regions were identified to contain SNPs suggestively associated with columnaris resistance $\left(-\log _{10}\right.$ (P-value $\left.)>4.16\right)$, although not statistically significant (Figure 3). As shown in Table 3, SNPs with relatively low $\mathrm{P}$ values were identified from the three suggestively associated regions on linkage groups 7,12 and 14.

The first suggestively associated region is on linkage group 7. About $12 \mathrm{Mb}$ downstream of the significantly associated region on linkage group 7, there is another locus suggestively associated with columnaris resistance. A series of SNPs on that region exhibit relatively low P values with the lowest ones listed on Table 3, with $\log _{10}$ (P-value) ranging from 4.83-5.12. In addition to linkage group 7, there are SNPs on linkage group 12 that reach suggestive genome-wide significance (P-value < 6.93e-5). The most significant SNP could explain 5.5\% of the variance. Compared with the region strongly associated with the columnaris resistance on linkage group 7 , the region detected on linkage group 12 is larger. According to the linkage map [27], the recombinant frequency is very low on this region of linkage group 12 . The distance of two most significant SNPs is $2.68 \mathrm{Mb}$ on linkage group 12 expanding about 2 centimorgans, while in catfish, on average, $1 \mathrm{cM}$ is equivalent to approximately $250 \mathrm{~Kb}$. According to the suggestively associated interspecific SNPs on linkage group 12, the resistant genotypes of the SNPs are homozygous with two channel catfish alleles, like the SNPs on linkage group 7. On linkage group 14, there is only one SNP reaching suggestive

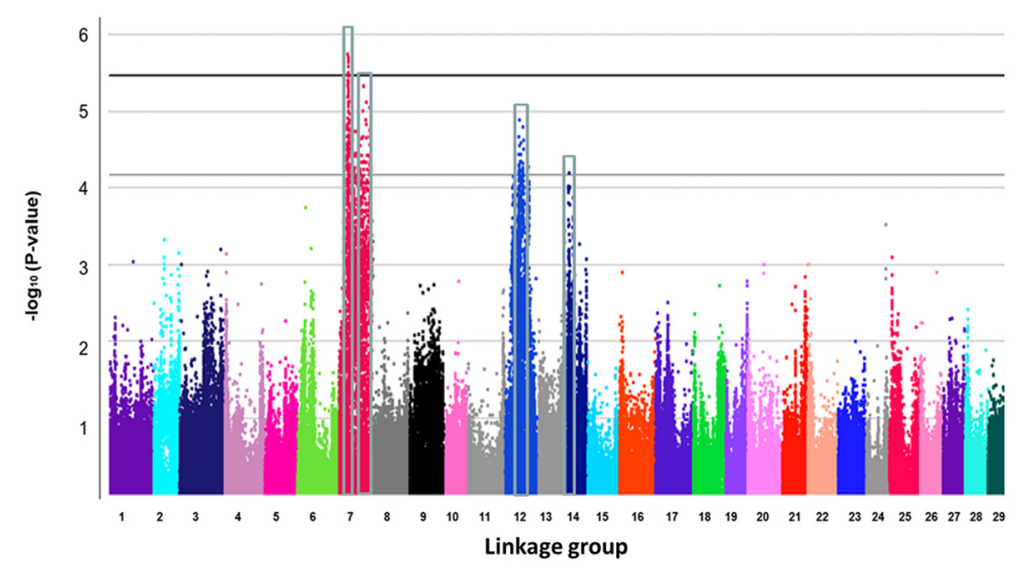

Figure 3 Manhattan plot of genome-wide association analysis for columnaris disease resistance. The black solid line indicates the threshold P-value for genome-wide significance. The gray solid line indicates the threshold P-value for the significance of "suggestive association". The four boxes indicate the associated regions. 
Table 2 The significantly associated SNPs on linkage group 7

\begin{tabular}{llll}
\hline SNP ID & $\begin{array}{l}\text { Position } \\
\text { (bp) }\end{array}$ & $\begin{array}{l}\text {-Log10 } \\
\text { (P-value) }\end{array}$ & Nearest gene \\
\hline AX-86060479 & 7252290 & 5.75 & upstream of pik3r3b \\
AX-85347098 & 7505396 & 5.70 & mast2 intron \\
AX-86056344 & 7633758 & 5.68 & adcyap1r1 exon \\
AX-85337705 & 7639440 & 5.65 & adcyap1r1 exon \\
AX-85377681 & 7569451 & 5.59 & downstream of akr1a1b \\
AX-85265763 & 7503336 & 5.51 & mast2 intron \\
AX-85240370 & 7203819 & 5.48 & upstream of pik3r3b \\
AX-85319066 & 7447662 & 5.47 & mast2 intron \\
AX-85346312 & 7618017 & 5.47 & adcyapir1 intron \\
AX-85378689 & 7755734 & 5.47 & zc3h3 intron \\
AX-85233717 & 7803806 & 5.47 & zc3h3 intron \\
AX-85260766 & 7817023 & 5.47 & zc3h3 intron \\
\hline
\end{tabular}

Bonferroni genome-wide significance, explaining $4.6 \%$ of the variance. The candidate genes surrounding the most significant SNPs of these 3 loci are listed in Table 3.

\section{Correlation of the SNPs associated with columnaris resistance}

Conditioned analyses were conducted to examine the correlation of the SNPs associated with columnaris resistance [23]. Genotypes of the most significant SNP (AX-86060479) on linkage group 7 were included as a covariate in the mixed linear model. After conditioning, the $-\log _{10}$ (P-value) of all the other SNPs on linkage group 7 dropped below 2.0, while the SNP P-values remained generally unchanged on the other linkage groups. On the linkage groups 12 and 14, there were also strong correlations among these associated SNPs within the same linkage group (data not shown).

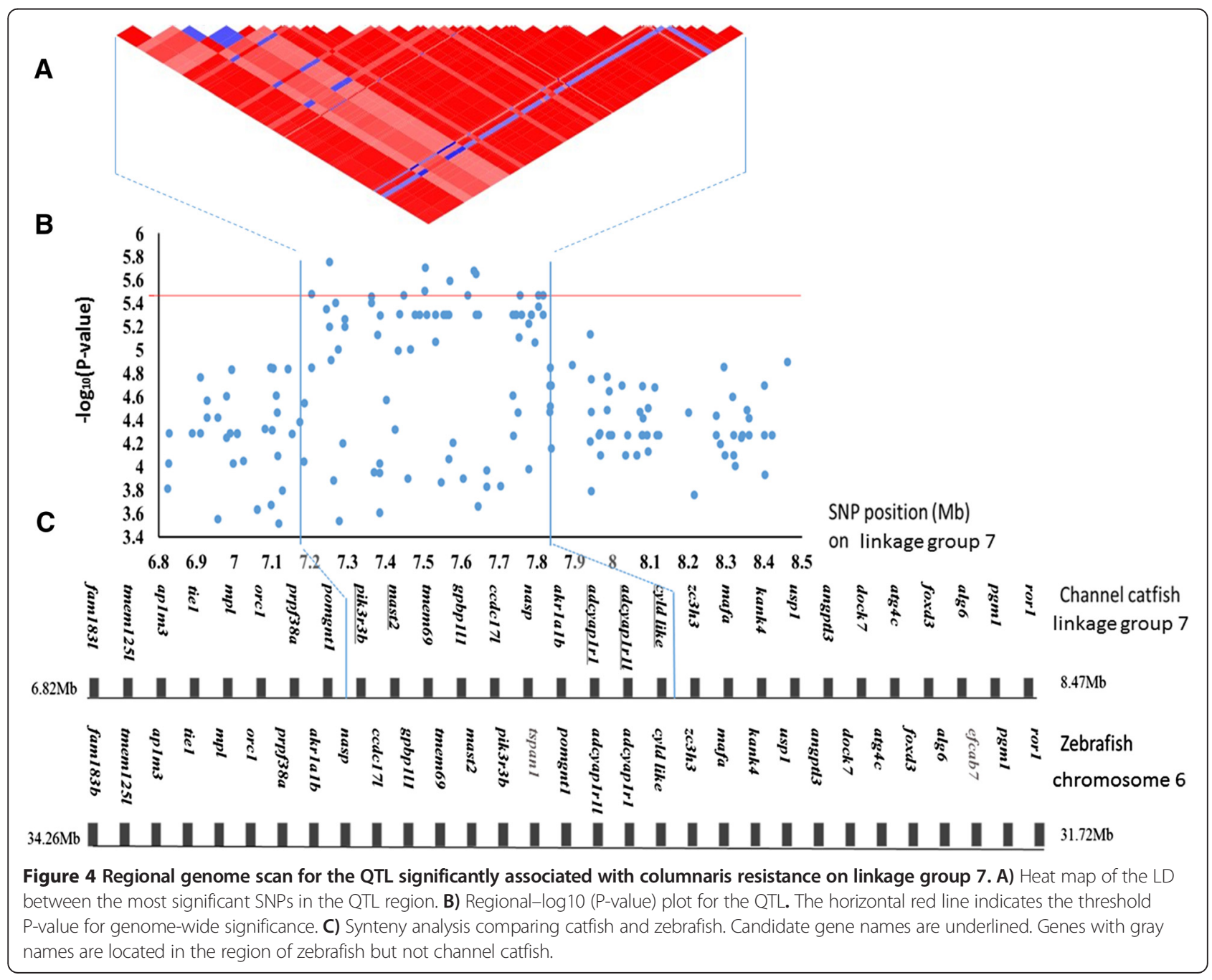


Table 3 The most significant SNPs with the closest and candidate genes in 3 suggestively associated regions

\begin{tabular}{|c|c|c|c|c|c|}
\hline $\begin{array}{l}\text { Linkage } \\
\text { group }\end{array}$ & SNP ID & $\begin{array}{l}\text { SNP position } \\
\text { (bp) }\end{array}$ & $\begin{array}{l}-\log _{10} \\
\text { (P-value) }\end{array}$ & Gene name & Gene position (bp) \\
\hline \multirow[t]{10}{*}{7} & AX-85432363 & 19715765 & 5.01 & cysteinyl leukotriene receptor 2 & 19913410, 19914493 \\
\hline & AX-85417541 & 20399460 & 5.33 & guanine nucleotide-binding protein (G protein) subunit beta $1^{*}$ & 19923349, 19927379 \\
\hline & AX-85231041 & 22082916 & 4.89 & voltage-dependent calcium channel subunit alpha $2 /$ delta $2^{\#}$ & 20083452,20300502 \\
\hline & AX-85406722 & 22298185 & 4.83 & hyaluronidase 2 & 20409454,20413226 \\
\hline & AX-85205344 & 22410724 & 5.12 & tumor suppressor candidate 2 & 20415941,20421024 \\
\hline & AX-85278425 & 25230627 & 5.12 & diphosphoinositol polyphosphate phosphohydrolase 1 & 20432914,20443526 \\
\hline & & & & protein kinase $C$ and casein kinase substrate in neurons protein 1 & 20469564,20487008 \\
\hline & & & & N-terminal EF-hand calcium-binding protein 1 & 22274849,22324281 \\
\hline & & & & alpha-1-syntrophin & 22377042,22408256 \\
\hline & & & & probable G-protein coupled receptor 27 & 25065312,25066872 \\
\hline \multirow[t]{5}{*}{12} & AX-85394454 & 12067569 & 4.89 & phosphatidylinositol 3-kinase regulatory subunit $5^{\dagger}$ & 12246367,12272207 \\
\hline & AX-85211547 & 14746472 & 4.79 & phosphatidylinositol 3-kinase regulatory subunit $6^{\dagger}$ & 12281638,12300055 \\
\hline & & & & guanine nucleotide-binding protein subunit beta $3^{*}$ & 12763269,12767890 \\
\hline & & & & voltage-dependent calcium channel gamma 6 subunit ${ }^{\#}$ & 14286927, 14292214 \\
\hline & & & & chondroitin sulfate proteoglycan 4 & 13668415,13668975 \\
\hline 14 & AX-85234783 & 1601158 & 4.20 & Spectrin beta chain, non-erythrocytic 2 & 1614033,1619504 \\
\hline
\end{tabular}

The paralogs are marked by different symbols following the gene names.

\section{Discussion}

In this study, for the first time, we identified a significantly associated QTL on linkage group 7 and three additional suggestive QTLs on linkage groups 7, 12, and 14 for columnaris resistance. The significant QTL on linkage group 7 was narrowed down to a small region of $620 \mathrm{~Kb}$. Therefore, in spite of being just an initial quantitative analysis for the complex disease resistance trait, this work is very significant because it has set the foundation for fine mapping of the columnaris resistance genes, providing basis for application of genome technologies for catfish aquaculture through marker- or genome-based selection. Additional fine mapping using larger or more families could narrow down the candidate genes underlining columnaris disease resistance.

A number of genes involved in the PI3K pathway were found to be within the significantly associated genomic region of $620 \mathrm{~Kb}$, suggesting the involvement of PI3K pathway in the resistance against columnaris. Among the 10 genes found in the $620 \mathrm{~Kb}$ region, five were involved in PI3K gene pathway. These are pik3r3b, cyld-like, adcyap1r1, adcyap1r1-like, and mast2. The phosphatidylinositol 3-kinase regulatory subunit gamma b (pik3r3b) is the closest gene to the most significantly associated SNP (AX-86060479) (Table 2). Although the causative SNP could be within any one of the 10 genes found in the $620 \mathrm{~Kb}$ region, the fact that PI3K pathway was reported to be involved in immunity and resistance makes them particularly interesting as candidate genes [28]. In addition, many genes found in the suggestive QTL regions were also involved in the PI3K pathway (see below), further increasing the likelihood of PI3K pathway involvement in the resistance against columnaris.

PI3 kinases have been known to play important roles in innate and adaptive immunity [28-31]. For example, PI3K activity is important for NF- $\mathrm{kB}$ pathway activation in different mechanisms [32,33]. It was also shown that the infectious agents can manipulate the PI3K pathway to create a favorable environment by various mechanisms [34]. PI3K is required for modifying the cytoskeleton dynamics, regulating membrane traffic, coordinating exocytic membrane insertion and pseudopod extension, which could be utilized by some pathogenic bacteria for entry into host cell [34-38]. Ireton et al. [34] showed that the protein InlB from Listeria monocytogenes is an agonist of mammalian PI3K, which causes rapid increases in cellular amounts of PI $(3,4) \mathrm{P}_{2}$ and PI $(3,4,5) \mathrm{P}_{3}$. Lambotin et al. [38] found Neisseria meningitidis requires cortactin recruitment by triggering a PI3K/Rac1 signaling to elicit an efficient invasion in non-phagocytic cells. Kierbel et al. [39] reported Pseudomonas aeruginosa requires the PI3K and Akt pathway for internalization. It was reported that Porphyromonas gingivalis could activate PI3K, which blocks phagocytosis and promotes inflammation [40]. In addition, it was shown that blockade or deficiency of PI3K $\gamma$ significantly enhanced resistance against Leishmania mexicana, which revealed the unique role for Class $\mathrm{I}_{\mathrm{B}} \mathrm{PI} 3 \mathrm{~K}$ in parasite invasion [41]. The fact that pik3r3b is closest to the most significant SNP makes it an interesting candidate for future studies. 
In addition to pik3r3b gene, four other genes (cyldlike, adcyap1r1, adcyap1r1-like, and mast2) in the PI3K pathway (Figure 5) found within the $620 \mathrm{~Kb}$ region containing the significant QTL have also been shown to play important roles in immunity. CYLD is a deubiquitylating enzyme that negatively regulates various signaling pathways by cleavaging lysine 63-linked polyubiquitin chains from several specific substrates [42]. For example, CYLD could regulate inflammation and the innate immune response via its inhibition of NF- $\mathrm{kB}$ activation [43]. Besides that, CYLD is a deubiquitinating enzyme for Akt and suppressed Akt activation [44]. Gao et al. [45] reported that CYLD also plays a role in the regulation of microtubule dynamics.

Pituitary adenylate cyclase-activating polypeptide type I receptor (ADCYAP1R1) is the pituitary adenylate cyclaseactivating polypeptide (PACAP) specific receptor [46]. PACAP could activate adenylate cyclase and phospholipase $C$ (PLC) through an interaction with ADCYAP1R1 and stimulates cAMP and inositol phosphate formation [47,48]. In fish larvae, Lugo et al. [49] reported that the PACAP influences immune functions. They observed an elevated level of nitric oxide synthase-derived metabolites and total immunoglobulin $M$ concentration in serum of juvenile catfish and tilapia after intraperitoneal injection of PACAP.

Microtubule-associated serine and threonine kinase 2 (MAST2) can interact with phosphatase and tensin homolog deleted on linkage group 10 (PTEN) which antagonizes PI3K-dependent signaling pathways [50,51]. MAST2 inhibits TNF receptor associated factor 6 (TRAF6) activity [52], which represents a molecular bridge for innate immunity and adaptive immunity [53]. For example, TRAF6 could activate PI3K-dependent cytoskeletal changes and activate IkB kinase (IKK) in response to proinflammatory cytokines [54]. Taken together, PI3 kinases themselves, or genes involved in PI3K pathway could play important roles in disease resistance.

Interestingly, many genes mapped within the suggestively associated QTL regions on linkage groups 7, 12, and 14 are functionally related to the genes mapped within the significant QTL region on linkage group 7, further supporting the possibility that PI3K pathway may be important for disease resistance against columnaris (Table 3, Figure 5). On linkage group 7, cysteinyl leukotriene receptor 2 is a $\mathrm{G}$ protein-coupled receptor (GPCR) with various functions such as modulation of chemokine gene transcription and calcium signaling $[55,56]$. $G$ beta gamma activates the class $\mathrm{I}_{\mathrm{B}} \mathrm{p} 110$ gamma/ p101 PI3K gamma on the stimulation of GPCR [57]. Voltage-dependent calcium channel subunit alpha-2/ delta-2 gene was found in this region, and PI3K could enhance native voltage-dependent calcium channel currents [58]. Diphosphoinositol polyphosphate phosphohydrolase 1 could cleave a beta-phosphate from the diphosphate groups in PP-InsP $\mathrm{P}_{5}$. PP-InsP $\mathrm{P}_{5}$ is similar to Ins $(1,3,4,5) \mathrm{P}_{4}$, the headgroup of $\mathrm{PI}(3,4,5) \mathrm{P}_{3}$, which implied their competition relationship [59]. Chockalingam [60] reported that alpha 1-syntrophin could bind PI $(4,5) \mathrm{P}_{2}$. Hyaluronidase2 , a glycosylphosphatidylinositol-anchored receptor, could hydrolyze hyaluronic acid which could be degraded by $F$. columnare [2]. On linkage group 12, the genes within the suggestive QTL region seemed to be related with those within the QTL region on linkage group 7, because the paralogs of some genes in this region on linkage group 12 are found on linkage group 7 including phosphatidylinositol 3-kinase regulatory subunit 5 (p101$P I 3 K)$, phosphatidylinositol 3-kinase regulatory subunit 6 (p87-PI3K), guanine nucleotide-binding protein subunit beta 3 , and voltage-dependent calcium channel gamma 6 subunit. On linkage group 14, spectrin beta chain, non-erythrocytic 2 ( $\beta I I I$ spectrin) is located

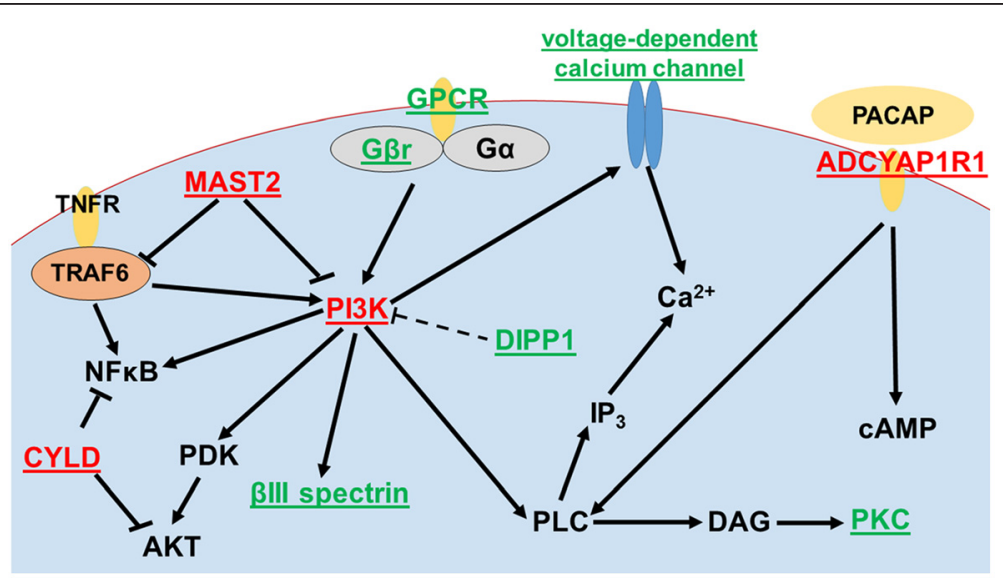

Figure 5 Signal transduction pathways involving PI3Ks and the other candidate genes. The candidate genes in the significant QTL are in red. The candidate genes in the suggestive QTLs are in green. 
closest to the most significant SNP (AX-85234783). With a $\mathrm{PH}$ domain, $\beta \mathrm{III}$ spectrin can bind $\mathrm{PIP}_{2}$ and get involved in membrane skeleton $[61,62]$. As presented in Figure 5, clearly many of these genes mapped in the significant QTL region or the suggestive QTL regions are involved in the related gene pathways.

It is notable that genes involved in the PI3K pathway were located together in "hubs" that were significantly associated with disease resistance. Theoretically, genes that are located together could be readily expressed in a coordinated fashion. However, here we do not have any evidence to indicate that the genes mapped within the QTLs involved in PI3K pathway are coordinately expressed. Analysis of RNA-seq data [20] indicated that some candidate genes indeed exhibited differences in baseline expression or after bacterial infection with columnaris. For instance, hyaluronidase- 2 was expressed at a relative higher level in resistant fish than in susceptible fish before infection, and it was induced more in susceptible fish than resistant fish after infection. Guanine nucleotide-binding protein subunit beta-1, another gene that mapped within the suggestive QTL region, is expressed significantly higher in the susceptible fish than in the resistant fish. After infection, its expression in susceptible fish, but not in resistant fish, was drastically induced. However, because the experimental system is quite different, such expression data may not be directly transferable to our results here.

The most striking finding of our study was that the genes closest to the most significant SNPs were both positionally and functionally related, i.e., they are structurally organized as "functional hubs". Although it is unknown at present whether these genes are expressed in a coordinated fashion, it was reported that neighboring genes tend to have similar expression patterns and get involved in related functions [63-65]. For instance, Schmid et al. [66] elucidated that genes in close proximity are much more likely to be co-expressed than expected by chance. Future analysis for coordinated expression of genes involved in PI3K pathway is warranted.

The QTLs identified in this study explained a limited fraction of the phenotypic variance of columnaris disease resistance. Firstly, the population specificity of QTLs is the most important reason why our family-based association mapping cannot detect all the QTLs associated with columnaris resistance [67]. Even within the same strain, various families showed drastically different susceptibilities to columnaris disease [68]. Secondly, segregating alleles within one species may lead to decreased power of analysis, especially in the case that one parental species systematically carries resistance alleles while the other one carries susceptibility alleles [69]. Thus the region cannot be detected with strong significance using intraspecific SNPs. The associated SNPs on linkage group 14 are intraspecific, so the effect of the locus may be underestimated and we cannot infer the origins of the resistant alleles. Thirdly, because of the lack of recombination between nearby QTLs, the locus with minor effect cannot be detected if the favorite allele on a close QTL with a major effect have a different origin. Lastly, but not leastly, genome level variations such as allele variations can account for only a fraction of phenotypic variations. Gene expression regulations at various levels such as transcriptional and posttranscriptional levels, as well as environment and genotypeenvironment interactions can have a profound impact on the final phenotype in performance.

\section{Conclusions}

In summary, our GWAS using backcross interspecific hybrid population allowed mapping of associated QTLs and estimation of their effects for columnaris resistance. On linkage groups 7 and 12, the resistant genotypes were homozygous with both alleles from channel catfish. Examination of genes in the mapped QTL regions allowed further analysis of candidate disease resistance genes. It appears that signal transduction pathways involving PI3Ks may play a crucial role for disease resistance against columnaris. This notion is not only supported by the presence of PI3K pathway genes in the significantly associated QTL on linkage group 7, but also by the fact that many genes within the suggestive QTL on linkage group 12 are paralogs of those found on linkage group 7. In addition, many genes found within suggestive QTLs on linkage groups 7, 12 and 14 are also involved in PI3K pathway. Future studies are required for the identification of the causative genes for disease resistance. For example, GWAS using larger or more families can be conducted to increase the power and resolution. Ultimately, gene knockout experiments are needed to demonstrate the candidate genes as the disease resistance genes.

The most interesting discovery of this work is that functionally related genes that may be responsible for columnaris disease resistance are located closely in a limited number of positions, forming "functional hubs". Future analysis of expression of genes in the PI3K pathway in relation to the resistance phenotype should determine whether the co-localized and functionally related genes are indeed expressed in a coordinated fashion.

\section{Methods}

\section{Ethics statement}

All experiments involving the handling and treatment of fish were approved by the Institutional Animal Care and Use Committee (IACUC) at Auburn University. Tissue samples were collected after euthanasia. All animal procedures were carried out according to the Guide for the 
Care and Use of Laboratory Animals and the Animal Welfare Act in the United States.

\section{Experimental fish, bacteria challenge and sample collection}

The study population was the Auburn University one year old catfish generated from back cross of male F1 hybrid catfish (female channel catfish $\times$ male blue catfish) with female channel catfish. The backcross progenies were produced by using the F1 as the male parent to avoid possible maternal effects in the early growth stage. The population consisted of six families. Since the offspring were mixed for culture, the genotypes of the samples could be used to assign the offspring into their families (see Table 1). Three reasons make us to choose the backcross family-based population as the study sample. First, the channel catfish $\times$ blue catfish interspecific system provides a useful research system for the understanding of columnaris resistance because they exhibit clear contrast in their phenotypes [4]. Segregation of genotypes in F2, along with the highly contrasted phenotypes, provides a good system for QTL analysis. Second, family-based association mapping is usually more powerful in detecting QTLs, since the lack of recombination between a QTL and linked marker increases the power of detection [70]. Third, family-based association mapping is preferred to detect rare markers related with QTLs [70].

1200 fish (average body weight 55.3 grams) were randomly obtained from Auburn University Fish Genetics Facility and acclimated for one week in the aerated flow-through water $[240 \times 60 \times 45 \mathrm{~cm}(\mathrm{~L} \times \mathrm{W} \times \mathrm{H})]$. The average water temperature was $25^{\circ} \mathrm{C}$. A total of 340 backcross progenies were selected from the extremes of the disease resistance distribution of the 1200 fish based on the selective genotyping method [24]. The first 169 fish that died of columnaris were continuously sampled as the susceptible group. When the fish lost balance, blood samples were collected. 171 fish that survived from the disease and showed no symptoms were selected randomly as the resistant group.

The bacteria challenge procedure was conducted as previously described [18]. The bacteria F. columnare were provided by the Aquatic Microbiology Laboratory, Auburn University. To get a single F. columnare colony, several fish were experimentally infected with a virulent isolate (BGFS-27; genomovar II) [71], and bacteria were re-isolated from one symptomatic fish after confirmed visually and biochemically. We selected BGFS-27 as representative of $F$. columnare for the present study, to which channel catfish was more resistant than blue catfish [4]. A single colony was cultured in modified Shieh broth for $24 \mathrm{~h}$ in a shaker incubator $(100 \mathrm{rpm})$ at $28^{\circ} \mathrm{C}$. The final concentration of the bacteria was determined using colony forming unit (CFU) per mL. Challenge experiments were then conducted by immersion exposure for $2 \mathrm{~h}$ at a final concentration of $3 \times 10^{6} \mathrm{CFU} / \mathrm{mL}$. Control fish were treated with identical procedures except that they were exposed to sterile modified Shieh broth.

\section{DNA isolation, genotyping, and quality control}

DNA was isolated using standard protocols. Briefly, the blood samples were incubated at $55^{\circ} \mathrm{C}$ overnight and DNA was extracted twice with phenol and once with chloroform. DNA was precipitated by isopropanol and collected by brief centrifugation, washed twice with $70 \%$ ethanol, air-dried, and resuspended in reduced EDTA TE buffer (10 mM Tris-HCl, 0.1 mM EDTA, pH 8.0). DNA was quantified using spectroscopy by Nanodrop (Thermo Scientific). The integrity of DNA samples was checked by $1 \%$ agarose gel electrophoresis stained with ethidium bromide. DNA was diluted to $50 \mathrm{ng} / \mathrm{uL}$ and the quality of genomic DNA satisfied the requirement for the genotyping platform of SNP arrays.

We have developed a catfish $250 \mathrm{~K}$ SNP array using Affymetrix Axiom genotyping technology [25,72]. Genotyping using the catfish $250 \mathrm{~K} \mathrm{SNP}$ array was performed at GeneSeek (Lincoln, Nebraska, USA). The informative SNPs in this GWAS were distributed across the catfish genome at an average interval of $3.6 \mathrm{~Kb}$. No sample was excluded due to low quality or low call rate $(<95 \%)$. 214,797 SNPs were kept after filtering out SNPs with an inheritance or genotyping error, a minor allele frequency (MAF) $<5 \%$, or a call rate $<95 \%$.

\section{Statistical analysis}

Statistical analysis was carried out using the SVS software package (SNP \& Variation Suite, Version 8.0). Pairwise linkage disequilibrium for the backcross progeny population was calculated according to $r^{2}$ value. LD pruning was conducted with a window size of 50 SNPs, a step of 5 SNPs, and $r^{2}$ threshold of 0.5 , resulting in 14,420 independent SNP markers. The population structure was assessed by principal component analysis with the independent SNP markers.

EMMAX (Efficient Mixed-Model Association eXpedited) analyses using all SNPs were conducted with the first two principal components and the fish body weight as covariates [73]. The model is as follows:

$$
\mathbf{Y}=\mathbf{X b}+\mathbf{Z} \mathbf{a}+\mathbf{e}
$$

where $\mathbf{Y}$ is the vector of phenotype; $\mathbf{b}$ is the vector of fixed effects including weight and first two principal components; $\mathbf{a}$ is the vector of random effects with covariance kinship matrix $\mathbf{G}$; $\mathbf{e}$ is the vector of random residuals; $\mathbf{X}$ and $\mathbf{Z}$ are coefficient matrices. 
The threshold P-value for genome-wide significance was calculated based on Bonferroni-correction with the estimated number of independent markers and LD blocks [74]. A Manhattan plot of the P-value results was produced using the SVS software. Although channel catfish and blue catfish are two species, apparently their genome architecture is extremely similar according to our former studies and unpublished data [75-77]. Thus, the genetic marker map was constructed according to channel catfish genome sequence.

\section{Sequence analysis}

The upstream and downstream genes of the significant SNPs were determined. GENSCAN program [78] and FGENESH+ [79] were used to analyze the catfish genome sequences (unpublished data) that surround the SNPs to identify the upstream and downstream genes. The identified genes were annotated by searching against the non-redundant protein database [80]. Genomicus [81] was utilized to construct the synteny of the counterpart genes from zebrafish to provide evidence for orthology.

\section{Availability of supporting data and requirements}

No new SNPs were discovered in this manuscript. The SNPs used in this manuscript are from the catfish $250 \mathrm{~K}$ SNP array [25]. The data sets supporting the results of this article are included within the article. The other information can be obtained from the corresponding author upon request.

\section{Competing interests}

The authors declare that they have no competing interests.

\section{Authors' contributions}

XG prepared the samples, conducted the statistical analysis and prepared the manuscript. DZ, JS and SL provided assistance for statistical analysis and manuscript preparation. SL, LB, JZ, RW, JY, CL, JF, FS, LS, CJ, YZ, AC, and RD were involved in fish culture, sample collection, and revising the manuscript. ZL supervised the entire study and provided assistance for manuscript preparation. All authors read and approved the final manuscript.

\section{Acknowledgements}

This project was supported by Agriculture and Food Research Initiative Competitive Grant no. 2015-67015-22975 from the USDA National Institute of Food and Agriculture (NIFA), and partially supported by USDA Aquaculture Research Program Competitive Grant no. 2014-70007-22395. The authors wish to thank Ludmilla Kaltenboeck and Huseyin Kucuktas for their technical assistance. X. Geng was supported by scholarships from the China Scholarship Council (CSC). X. Geng received a Travel Award from Short Course on Statistical Genetics and Genomics at UAB (Grant No. R25GM093044). D. Zhi was supported by an NIH grant (R01 HG008115).

Received: 7 November 2014 Accepted: 27 February 2015 Published online: 17 March 2015

\section{References}

1. Plumb JA, Hanson LA, Plumb JA. Health maintenance and principal: microbial diseases of cultured fishes. 3rd ed. Wiley-Blackwell: Ames, lowa; 2011.
2. Declercq AM, Haesebrouck F, Van den Broeck W, Bossier P, Decostere A. Columnaris disease in fish: a review with emphasis on bacterium-host interactions. Vet Res. 2013:44(1):27-44

3. Hawke JP, Thune RL. Systemic isolation and antimicrobial susceptibility of Cytophaga columnaris from commercially reared channel catfish. J Aquat Anim Health. 1992:4(2):109-13.

4. Arias CR, Cai W, Peatman E, Bullard SA. Cattish hybrid Ictalurus punctatus $\times 1$. furcatus exhibits higher resistance to columnaris disease than the parental species. Dis Aquat Organ. 2012;100(1):77-81.

5. Birchler JA, Auger DL, Riddle NC. In search of the molecular basis of heterosis. The Plant Cell Online. 2003;15(10):2236-9.

6. Giudice JJ. Growth of a blue $\times$ channel catfish hybrid as compared to its parent species. The Progressive Fish-Culturist. 1966;28(3):142-5.

7. Dunham RA, Umali GM, Beam R, Kristanto AH, Trask M. Comparison of production traits of NWAC103 channel catfish, NWAC103 channel catfish $\times$ blue catfish hybrids, Kansas select 21 channel catfish, and blue catfish grown at commercial densities and exposed to natural bacterial epizootics. N Am J Aquac. 2008;70(1):98-106.

8. Moen T, Baranski M, Sonesson AK, Kjøglum S. Confirmation and finemapping of a major QTL for resistance to infectious pancreatic necrosis in Atlantic salmon (Salmo salar): population-level associations between markers and trait. BMC Genomics. 2009;10(1):368-82.

9. Gheyas A, Haley C, Guy D, Hamilton A, Tinch A, Mota-Velasco J, et al. Effect of a major QTL affecting IPN resistance on production traits in Atlantic salmon. Anim Genet. 2010;41(6):666-8.

10. Gheyas A, Houston R, Mota-Velasco J, Guy D, Tinch A, Haley C, et al. Segregation of infectious pancreatic necrosis resistance QTL in the early life cycle of Atlantic Salmon (Salmo salar). Anim Genet. 2010;41(5):531-6.

11. Phillips R, Ventura A, Dekoning J, Nichols K. Mapping rainbow trout immune genes involved in inflammation reveals conserved blocks of immune genes in teleosts. Anim Genet. 2013;44(1):107-13.

12. Houston RD, Davey JW, Bishop SC, Lowe NR, Mota-Velasco JC, Hamilton A, et al. Characterisation of QTL-linked and genome-wide restriction siteassociated DNA (RAD) markers in farmed Atlantic salmon. BMC Genomics. 2012;13(1):244

13. Houston R, Gheyas A, Hamilton A, Guy D, Tinch A, Taggart J, et al. Detection and confirmation of a major QTL affecting resistance to infectious pancreatic necrosis (IPN) in Atlantic salmon (Salmo salar). Dev Biol. 2008;132:199-204

14. Li C, Zhang Y, Wang R, Lu J, Nandi S, Mohanty S, et al. RNA-seq analysis of mucosal immune responses reveals signatures of intestinal barrier disruption and pathogen entry following Edwardsiella ictaluri infection in channel catfish, Ictalurus punctatus. Fish Shellfish Immunol. 2012;32(5):816-27.

15. Wang R, Sun L, Bao L, Zhang J, Jiang Y, Yao J, et al. Bulk segregant RNA-seq reveals expression and positional candidate genes and allele-specific expression for disease resistance against enteric septicemia of catfish. BMC Genomics. 2013;14(1):929-47.

16. Decostere A, Haesebrouck F, Van Driessche E, Charlier G, Ducatelle R. Characterization of the adhesion of Flavobacterium columnare (Flexibacter columnaris) to gill tissue. J Fish Dis. 1999;22(6):465-74.

17. Olivares-Fuster O, Bullard SA, McElwain A, Llosa MJ, Arias CR. Adhesion dynamics of Flavobacterium columnare to channel catfish Ictalurus punctatus and zebrafish Danio rerio after immersion challenge. Dis Aquat Organ. 2011;96(3):221-7.

18. Sun F, Peatman E, Li C, Liu S, Jiang Y, Zhou Z, et al. Transcriptomic signatures of attachment, NF-kappaB suppression and IFN stimulation in the catfish gill following columnaris bacterial infection. Dev Comp Immunol. 2012;38(1):169-80.

19. Beck BH, Farmer BD, Straus DL, Li C, Peatman E. Putative roles for a rhamnose binding lectin in Flavobacterium columnare pathogenesis in channel catfish Ictalurus punctatus. Fish Shellfish Immunol. 2012;33(4):1008-15.

20. Peatman E, Li C, Peterson BC, Straus DL, Farmer BD, Beck BH. Basal polarization of the mucosal compartment in Flavobacterium columnare susceptible and resistant channel catfish (Ictalurus punctatus). Mol Immunol. 2013;56(4):317-27.

21. Li F, Chen B, Xu K, Wu J, Song W, Bancroft I, et al. Genome-wide association study dissects the genetic architecture of seed weight and seed quality in rapeseed (Brassica napus L.). DNA Res. 2014;21(4):355-67.

22. Gu X, Feng C, Ma L, Song C, Wang Y, Da Y, et al. Genome-wide association study of body weight in chicken F2 resource population. PLoS One. 2011;6(7):e21872. 
23. Nishimura S, Watanabe T, Mizoshita K, Tatsuda K, Fujita T, Watanabe N, et al. Genome-wide association study identified three major QTL for carcass weight including the PLAG1-CHCHD7 QTN for stature in Japanese Black cattle. BMC Genet. 2012;13(1):40-51.

24. Darvasi A, Soller M. Selective genotyping for determination of linkage between a marker locus and a quantitative trait locus. Theor Appl Genet. 1992;85(2-3):353-9.

25. Liu S, Sun L, Li Y, Sun F, Jiang Y, Zhang Y, et al. Development of the catfish 250 K SNP array for genome-wide association studies. BMC Research Notes. 2014:7(1):135-47.

26. Pruitt KD, Tatusova T, Maglott DR. NCBI reference sequences (RefSeq): a curated non-redundant sequence database of genomes, transcripts and proteins. Nucleic Acids Res. 2007;35 suppl 1:D61-5

27. Li Y, Liu S, Qin Z, Waldbieser G, Wang R, Sun L, et al. Construction of a highdensity, high-resolution genetic map and its integration with BAC-based physical map in channel catfish. DNA Res. 2015;22(1):39-52.

28. Koyasu S. Role of phosphatidylinositol 3-kinase in the immune system. Tanpakushitsu Kakusan Koso. 2006;51(11):1569-79.

29. Jiang K, Zhong B, Gilvary DL, Corliss BC, Hong-Geller E, Wei S, et al. Pivotal role of phosphoinositide-3 kinase in regulation of cytotoxicity in natural killer cells. Nat Immunol. 2000;1(5):419-25.

30. Vieira OV, Botelho RJ, Rameh L, Brachmann SM, Matsuo T, Davidson HW, et al. Distinct roles of class I and class III phosphatidylinositol 3-kinases in phagosome formation and maturation. J Cell Biol. 2001;155(1):19-25.

31. Fukao T, Tanabe M, Terauchi Y, Ota T, Matsuda S, Asano T, et al. PI3Kmediated negative feedback regulation of IL-12 production in DCs. Nat Immunol. 2002;3(9):875-81.

32. Bone $H$, Williams NA. Antigen-receptor cross-linking and lipopolysaccharide trigger distinct phosphoinositide 3-kinase-dependent pathways to NF-kappa B activation in primary B cells. Int Immunol. 2001;13(6):807-16.

33. Reddy SAG, Huang JH, Liao WSL. Phosphatidylinositol 3-kinase in interleukin 1 signaling-Physical interaction with the interleukin 1 receptor and requirement in NF kappa B and AP-1 activation. J Biol Chem. 1997;272(46):29167-73.

34. Ireton $K$, Payrastre $B$, Cossart $P$. The Listeria monocytogenes protein InIB is an agonist of mammalian phosphoinositide 3-kinase. J Biol Chem. 1999;274(24):17025-32.

35. Cox D, Tseng CC, Bjekic G, Greenberg S. A requirement for phosphatidylinositol 3-kinase in pseudopod extension. J Biol Chem. 1999;274(3):1240-7.

36. Ireton K, Payrastre B, Chap H, Ogawa W, Sakaue H, Kasuga M, et al. A role for phosphoinositide 3-kinase in bacterial invasion. Science. 1996;274(5288):780-2.

37. Pizarro-Cerda J, Cossart P. Bacterial adhesion and entry into host cells. Cell. 2006;124(4):715-27.

38. Lambotin M, Hoffmann I, Laran-Chich MP, Nassif X, Couraud PO, Bourdoulous $S$. Invasion of endothelial cells by Neisseria meningitidis requires cortactin recruitment by a phosphoinositide-3-kinase/Rac1 signalling pathway triggered by the lipo-oligosaccharide. J Cell Sci. 2005;118(Pt 16):3805-16.

39. Kierbel A, Gassama-Diagne A, Mostov K, Engel JN. The phosphoinositol-3kinase-protein kinase B/Akt pathway is critical for Pseudomonas aeruginosa strain PAK internalization. Mol Biol Cell. 2005;16(5):2577-85.

40. Maekawa T, Krauss JL, Abe T, Jotwani R, Triantafilou M, Triantafilou K, et al. Porphyromonas gingivalis Manipulates Complement and TLR Signaling to Uncouple Bacterial Clearance from Inflammation and Promote Dysbiosis. Cell Host Microbe. 2014;15(6):768-78.

41. Cummings HE, Barbi J, Reville P, Oghumu S, Zorko N, Sarkar A, et al. Critica role for phosphoinositide 3-kinase gamma in parasite invasion and disease progression of cutaneous leishmaniasis. Proc Natl Acad Sci U S A. 2012;109(4):1251-6.

42. Massoumi R. Ubiquitin chain cleavage: CYLD at work. Trends Biochem Sci. 2010;35(7):392-9.

43. Sun SC. CYLD: a tumor suppressor deubiquitinase regulating NF-kappa B activation and diverse biological processes. Cell Death Differ. 2010;17(1):25-34

44. Yang W-L, Jin G, Li C-F, Jeong YS, Moten A, Xu D, et al. Cycles of ubiquitination and deubiquitination critically regulate growth factor-mediated activation of Akt signaling. Sci Signal. 2013;6(257):ra3.

45. Gao J, Huo L, Sun X, Liu M, Li D, Dong J-T, et al. The tumor suppressor CYLD regulates microtubule dynamics and plays a role in cell migration. J Biol Chem. 2008;283(14):8802-9.
46. Arimura A, Shioda S. Pituitary adenylate cyclase activating polypeptide (PACAP) and its receptors: neuroendocrine and endocrine interaction. Front Neuroendocrinol. 1995;16(1):53-88.

47. Romanelli F, Fillo S, Isidori A, Conte D. Pituitary adenylate cyclase-activating polypeptide regulates rat Leydig cell function in vitro. Neuropeptides. 1997;31(4):311-7.

48. Bodart V, Babinski K, Ong H, De Lean A. Comparative effect of pituitary adenylate cyclase-activating polypeptide on aldosterone secretion in normal bovine and human tumorous adrenal cells. Endocrinology. 1997;138(2):566-73.

49. Lugo JM, Carpio Y, Oliva A, Morales A, Estrada MP. Pituitary adenylate cyclase-activating polypeptide (PACAP): a regulator of the innate and acquired immune functions in juvenile fish. Fish Shellfish Immunol. 2010;29(3):513-20.

50. Downes C, Bennett D, McConnachie G, Leslie N, Pass I, MacPhee C, et al. Antagonism of PI 3-kinase-dependent signalling pathways by the tumour suppressor protein, PTEN. Biochem Soc Trans. 2001;29(Pt 6):846-51.

51. Terrien E, Chaffotte A, Lafage M, Khan Z, Prehaud C, Cordier F, et al. Interference with the PTEN-MAST2 interaction by a viral protein leads to cellular relocalization of PTEN. Sci Signal. 2012;5(237):ra58.

52. Xiong $\mathrm{H}$, Li H, Chen Y, Zhao J, Unkeless JC. Interaction of TRAF6 with MAST205 regulates NF-kappaB activation and MAST205 stability. J Biol Chem. 2004;279(42):43675-83

53. Wu H, Arron JR. TRAF6, a molecular bridge spanning adaptive immunity, innate immunity and osteoimmunology. Bioessays. 2003;25(11):1096-105.

54. Wang KZ, Wara-Aswapati N, Boch JA, Yoshida Y, Hu C-D, Galson DL, et al. TRAF6 activation of PI 3-kinase-dependent cytoskeletal changes is cooperative with Ras and is mediated by an interaction with cytoplasmic Src. J Cell Sci. 2006;119(8):1579-91.

55. Thompson C, Cloutier A, Bossé Y, Poisson C, Larivée P, McDonald PP, et al. Signaling by the Cysteinyl-Leukotriene Receptor 2 involvement in chemokine gene transcription. J Biol Chem. 2008;283(4):1974-84.

56. Sjöström M, Johansson A-S, Schröder O, Qiu H, Palmblad J, Haeggström JZ. Dominant expression of the Cys $L T 2$ receptor accounts for calcium signaling by cysteinyl leukotrienes in human umbilical vein endothelial cells. Arterioscler Thromb Vasc Biol. 2003;23(8):e37-41.

57. Brock C, Schaefer M, Reusch HP, Czupalla C, Michalke M, Spicher K, et al. Roles of $\mathrm{G}$ beta gamma in membrane recruitment and activation of p110 gamma/ p101 phosphoinositide 3-kinase gamma. J Cell Biol. 2003;160(1):89-99.

58. Viard P, Butcher AJ, Halet G, Davies A, Nürnberg B, Heblich F, et al. PI3K promotes voltage-dependent calcium channel trafficking to the plasma membrane. Nat Neurosci. 2004;7(9):939-46.

59. Shears SB. Diphosphoinositol polyphosphates: metabolic messengers? Mol Pharmacol. 2009;76(2):236-52.

60. Chockalingam PS, Gee SH, Jarrett HW. Pleckstrin homology domain 1 of mouse a1-syntrophin binds phosphatidylinositol 4, 5-bisphosphate. Biochemistry. 1999;38(17):5596-602.

61. Viel A, Branton D. Spectrin: on the path from structure to function. Curr Opin Cell Biol. 1996;8(1):49-55.

62. Holleran EA, Ligon LA, Tokito M, Stankewich MC, Morrow JS, Holzbaur EL. beta III spectrin binds to the Arp1 subunit of dynactin. J Biol Chem. 2001;276(39):36598-605.

63. Williams EJ, Bowles DJ. Coexpression of neighboring genes in the genome of Arabidopsis thaliana. Genome Res. 2004;14(6):1060-7.

64. Michalak P. Coexpression, coregulation, and cofunctionality of neighboring genes in eukaryotic genomes. Genomics. 2008;91(3):243-8.

65. Sémon M, Duret L. Evolutionary origin and maintenance of coexpressed gene clusters in mammals. Mol Biol Evol. 2006:23(9):1715-23.

66. Schmid M, Davison TS, Henz SR, Pape UJ, Demar M, Vingron M, et al. A gene expression map of Arabidopsis thaliana development. Nat Genet. 2005;37(5):501-6.

67. Luo C, Qu H, Ma J, Wang J, Li C, Yang C, et al. Genome-wide association study of antibody response to Newcastle disease virus in chicken. BMC Genet. 2013;14(1):42-51.

68. LaFrentz BR, Shoemaker CA, Booth NJ, Peterson BC, Ourth DD. Spleen index and mannose-binding lectin levels in four channel catfish families exhibiting different susceptibilities to Flavobacterium columnare and Edwardsiella ictaluri. J Aquat Anim Health. 2012;24(3):141-7.

69. Ledur M, Navarro N, Pérez-Enciso M. Large-scale SNP genotyping in crosses between outbred lines: how useful is it ? Heredity. 2009;105(2):173-82.

70. Mackay I, Powell W. Methods for linkage disequilibrium mapping in crops. Trends Plant Sci. 2007;12(2):57-63. 
71. Olivares-Fuster O, Arias CR. Development and characterization of rifampicinresistant mutants from high virulent strains of Flavobacterium columnare. J Fish Dis. 2011;34(5):385-94.

72. Liu S, Zhou Z, Lu J, Sun F, Wang S, Liu H, et al. Generation of genome-scale gene-associated SNPs in catfish for the construction of a high-density SNP array. BMC Genomics. 2011:12:53-66.

73. Kang HM, Sul JH, Service SK, Zaitlen NA, Kong S-y, Freimer NB, et al. Variance component model to account for sample structure in genome-wide association studies. Nat Genet. 2010;42(4):348-54.

74. Duggal P, Gillanders EM, Holmes TN, Bailey-Wilson JE. Establishing an adjusted p-value threshold to control the family-wide type 1 error in genome wide association studies. BMC Genomics. 2008;9(1):516-24.

75. Liu Z, Karsi A, Li P, Cao D, Dunham R. An AFLP-based genetic linkage map of channel catfish (Ictalurus punctatus) constructed by using an interspecific hybrid resource family. Genetics. 2003;165(2):687-94.

76. Kucuktas H, Wang S, Li P, He C, Xu P, Sha Z, et al. Construction of genetic linkage maps and comparative genome analysis of catfish using geneassociated markers. Genetics. 2009;181(4):1649-60.

77. Ninwichian P, Peatman E, Liu H, Kucuktas H, Somridhivej B, Liu S, et al. Second-generation genetic linkage map of catfish and its integration with the BAC-based physical map. G3: Genes| Genomes| Genetics. 2012;2(10):1233-41.

78. Burge C, Karlin S. Prediction of complete gene structures in human genomic DNA. J Mol Biol. 1997;268(1):78-94.

79. Salamov AA, Solovyev W. Ab initio gene finding in Drosophila genomic DNA. Genome Res. 2000;10(4):516-22.

80. Altschul SF, Gish W, Miller W, Myers EW, Lipman DJ. Basic local alignment search tool. J Mol Biol. 1990;215(3):403-10

81. Muffato M, Louis A, Poisnel C-E, Crollius HR. Genomicus: a database and a browser to study gene synteny in modern and ancestral genomes. Bioinformatics. 2010;26(8):1119-21.

\section{Submit your next manuscript to BioMed Central and take full advantage of:}

- Convenient online submission

- Thorough peer review

- No space constraints or color figure charges

- Immediate publication on acceptance

- Inclusion in PubMed, CAS, Scopus and Google Scholar

- Research which is freely available for redistribution 